\title{
Diagnóstico para implantação do balanced scorecard: um estudo de caso em uma empresa de pequeno porte
}

\author{
Diagnostic for deployment of the balanced scorecard: a case study in a small business
}

Vânia Santos da Cunha Camboim ${ }^{[a]}$, Larissa Alves de Azevedo ${ }^{[b]}$, Susie Alves Silva de Macêdo ${ }^{[c]}$, Jamerson Viegas Queiroz ${ }^{[\mathrm{d}]}$, Fernanda Cristina Barbosa Pereira Queiroz ${ }^{[\mathrm{e}]}$

[a] Mestranda em Engenharia de Produção pela Universidade Federal do Rio Grande do Norte (UFRN), Natal, RN - Brasil, e-mail: vaniascunha@hotmail.com

[b] Bacharel em Administração pela Universidade Federal do Rio Grande do Norte (UFRN), Natal, RN - Brasil, e-mail: larissa.alvesaz@gmail.com

[c] Mestre em Administração pela Universidade Potiguar (UNP), diretora de Desenvolvimento Tecnológico e Inovação pela Fundação de Apoio e Pesquisa do Estado do Rio Grande do Norte (FAPERN), Natal, RN - Brasil, e-mail: susieasmacedo@gmail.com

[d] Doutor em Engenharia de Produção pela Universidade de Santa Catarina (UFSC), professor adjunto da Pós-Graduação em Engenharia de Produção pela Universidade Federal do Rio Grande do Norte (UFRN), Natal, RN - Brasil, e-mail: jvq@ufrnet.br

[e] Doutora em Engenharia de Produção pela Universidade Federal de Santa Catarina (UFSC), professora adjunta da PósGraduação em Engenharia de Produção pela Universidade Federal do Rio Grande do Norte (UFRN), Natal, RN - Brasil, e-mail: fernandacbpereira@yahoo.com.br

\section{Resumo}

0 estudo do presente artigo tem o objetivo de identificar indicadores de desempenho, baseados na metodologia do BSC, aplicados a uma pequena empresa do ramo de equipamentos do Rio Grande do Norte. A metodologia utilizada baseou-se em uma pesquisa aplicada, descritiva e explicativa, a partir da utilização de um questionário composto por perguntas abertas e fechadas. A análise de dados se deu de forma qualitativa. Os principais resultados foram o mapeamento das estratégias do negócio adotadas pela empresa e, ao mesmo tempo, traçar diretrizes para a mesma, configurando-se, dessa forma, em um estudo de caso. Constata-se que a aplicação do modelo proposto poderá contribuir e alavancar os processos de negócio-chave, monitorar o desempenho, traçar diretrizes que proporcionem vantagens competitivas mais eficazes, alicerçadas por dados reais do mercado, além de reduzir custos inerentes às atividades meio e fim, propiciando, dentre outras vantagens, consolidar processos inovadores e empreendedores.

Palavras-chave: Balanced scorecard. Indicadores de desempenho. Estratégia.

\section{Abstract}

The study of this paper is to identify performance indicators, based on the BSC methodology, applied to a small company's line of equipment RN. The methodology used was based on an applied research, descriptive and explanatory from the use of a questionnaire composed of open and closed questions, as well as the analysis of data was a 
qualitative way. The main results were mapping the business strategies adopted by the company and at the same time, set guidelines for the same, becoming, thus, in a case study. It appears that the application of the proposed model can contribute to and leverage the key business processes, monitor performance, set guidelines that provide more effective competitive advantage, underpinned by real market data, and reduce costs through the activities and finally, providing among other advantages, consolidate processes and entrepreneurs.

Keywords: Balanced scorecard. Performance indicators. Strategy.

\section{Introdução}

Diante do atual ambiente globalizado e da competitividade acirrada que há entre as organizações, novas formas de gerenciamento são buscadas pelas empresas para poderem se manter e se diferenciar no mercado. A partir deste contexto, o Balanced Scorecard é apresentado como uma ferramenta organizacional que preserva os indicadores financeiros como a síntese final do desempenho gerencial e organizacional, mas incorpora um conjunto de medidas mais genérico e integrado que vincula o desempenho sob a ótica dos clientes, processos internos, funcionários e sistemas ao sucesso financeiro.

A abordagem do BSC foi proposta por Robert Kaplan e David Norton através de um artigo publicado na Harvard Business Review, em 1992. Apesar de recente, o método vem sendo utilizado por grandes organizações ao redor do mundo e já tem despertado interesse das organizações de menor porte. 0 sucesso da abordagem se deve, entre outras coisas, a sua simplicidade e forte capacidade de estabelecer a correlação entre a visão da organização e as ações do dia a dia.

Dentro deste contexto, a empresa estudada atua no mercado potiguar desde 1983, com um mix de produtos muito variado de artigos de utilidades a equipamentos industriais para hotéis, restaurantes e comércio em geral. Atualmente, opera com duas lojas, uma média de 5 mil itens a venda e cerca de 40 funcionários. É uma empresa familiar com uma cultura forte e enraizada, a rotatividade de funcionários é pequena e o espírito empreendedor de seus gestores caracteriza seu crescimento no segmento que atua. 0 presente estudo se justifica diante da necessidade de identificação e mensuração de indicadores de desempenho da empresa, que atualmente não utiliza nenhum método específico de medição de custos, despesas, receitas, clientes e processos. Deste modo, pretende-se responder à seguinte situação problema: Como mensurar e controlar indicadores de gestão para a obtenção de melhores resultados financeiros e não financeiros em uma empresa de pequeno porte? Para responder a este questionamento, a presente pesquisa tem como objetivo: identificar indicadores de desempenho, baseados na metodologia do BSC, aplicados a uma pequena empresa do ramo de equipamentos do Rio Grande do Norte. Mediante os objetivos específicos: (a) sugerir um sistema de medição de desempenho, com base no Balanced Scorecard, e (b) traçar diretrizes em consonância às iniciativas estratégicas utilizadas, analisando-as a partir das quatro perspectivas sugeridas pelo $B S C$.

Desta forma, a organização do presente artigo inicia-se com uma abordagem introdutória, seguida pela seção 2, fundamentação teórica; a seção 3, metodologia; e os resultados na seção 4. Posteriormente, na seção 5 , encontram-se as considerações finais do estudo, além de sugestões para possíveis trabalhos futuros. E, por fim, as referências para a fundamentação deste estudo.

\section{Fundamentação teórica}

Segundo o pensamento de Kaplan e Norton (1997), medir é importante: “O que não é medido não é gerenciado". 0 sistema de indicadores afeta o comportamento das pessoas dentro e fora da empresa. Para que sejam bem-sucedidas na era da informação, as empresas precisam utilizar sistemas de gestão e medição de desempenho derivados de suas estratégias e capacidades, as medidas financeiras do desempenho passado são complementadas com as medidas dos vetores que impulsionam o desempenho futuro. Segundo Azarbad et al. (2011), o BSC cria causa e efeito entre os modelos de interação entre gerentes, funcionários e a organização como um todo. Os objetivos e medidas do Balanced Scorecard derivam da visão e estratégia da empresa e focalizam o desempenho organizacional sob quatro perspectivas, as quais 
formam a sua estrutura: financeira, do cliente, dos processos internos e de aprendizado e crescimento.

o Balanced Scorecard reflete o equilíbrio entre os objetivos de curto e longo prazo, entre medidas financeiras e não financeiras, entre indicadores de tendências e ocorrências e entre perspectivas interna e externa (KAPLAN; NORTON, 1997). Com a utilização do Balanced Scorecard, os gestores passam a ter um instrumento para avaliar até que ponto suas unidades de negócios geram valor para os clientes atuais e futuros e como devem aperfeiçoar as capacidades internas e os investimentos necessários em pessoal, sistemas e procedimentos, visando melhorar o desempenho futuro. "Torna-se imprescindível definir e implementar uma sistemática de indicadores gerenciais capazes de fornecer aos gestores informações sobre vários aspectos do ambiente e do desempenho organizacional" (LUZ, 2009). Segundo Kaplan e Norton (2000, p. 11), "a capacidade de executar a estratégia é mais importante do que a qualidade da estratégia em si".

Durante o processo de planejamento, as organizações estabelecem objetivos estratégicos que não são de natureza meramente financeira, como satisfação de clientes, ciclo de desenvolvimento de produtos e grau de inovação. Esse é um dos fatos que justifica a necessidade de se adotar modelos de avaliação que contemplem os aspectos não financeiros. Segundo Mello et al. (2010), o BSC é o método mais indicado para medir e monitorar os ativos intangíveis, pois é um modelo de sistemática gerencial capaz de materializar a visão futura.

Para Costa (2006), o BSC é uma particular maneira de tratar da definição e da disposição das informações-chave para gerenciar o cumprimento da estratégia da empresa (mapa estratégico), e dos processos gerenciais que promovem o alinhamento estratégico necessário para tal definição (comunicação, vinculação e referência fundamental).

Para Kaplan e Norton (2000, p. 12), "um problema é que as estratégias estão mudando, mas as ferramentas para a mensuração das estratégias ficaram para trás". Quando Kaplan e Norton desenvolveram o BSC, a princípio achavam que o modelo tratava de mensuração e não de estratégia. Partiram da premissa de que a confiança exclusiva em indicadores financeiros estava induzindo as empresas a opções errôneas.

Para tanto, os autores propõem que a implantação do Balanced Scorecard seja demonstrada através do desenho do mapa estratégico, que tem por finalidade decodificar os complexos processos de escolha frente aos quais os gestores de todos os níveis são expostos diariamente. É mediante o mapa estratégico que a alta administração monitora o cumprimento da estratégia. 0 mapa estratégico é o meio pelo qual se operacionaliza a vinculação do planejamento estratégico e o planejamento operacional.

\section{Perspectiva financeira}

Segundo Costa (2006), as medidas financeiras indicam se a empresa está obtendo êxito com as estratégias definidas, implementadas e executadas. Em geral, esse êxito é medido pela lucratividade, pelo crescimento do negócio e pelo incremento do valor para o acionista. Se os indicadores financeiros não mostram o esperado, pode haver problemas na execução, na implementação ou até mesmo na definição das estratégias.

Normalmente, as empresas definem objetivos financeiros e medidas financeiras genéricos, que expressam essencialmente o resultado final esperado. O mapa estratégico requer um detalhamento maior para que possa efetivamente indicar como a empresa acredita poder alcançar o desempenho esperado nesses itens. Portanto, além das medidas de resultado, é preciso ainda, na perspectiva financeira, definir alguns objetivos e medidas específicas, chamadas no modelo de medidas de tendência.

Os indicadores financeiros, em cada fase, então, devem expressar o tipo de decisão estratégica que será tomada. Os objetivos financeiros de longo prazo devem nortear as ações de curto e médio prazo. Assim, não se deve gerir os indicadores operacionais sem ter em conta os reflexos que geram nos indicadores financeiros.

Para Kaplan e Norton (1997), os objetivos financeiros servem de foco para os objetivos e medidas das outras perspectivas do scorecard. Qualquer medida selecionada deve fazer uma cadeia de relações de causa e efeito que culminam com a melhoria do desempenho financeiro. O BSC deve contar a história da estratégia, começando pelos objetivos financeiros de longo prazo e relacionando-os depois às sequências de ações que precisam ser tomadas em relação aos processos financeiros, dos clientes, dos processos internos e, por fim, dos funcionários e sistemas, a fim de que, a longo prazo, seja produzido o desempenho econômico. 
Os objetivos financeiros podem diferir consideravelmente em casa fase do ciclo de vida de uma empresa. A teoria da estratégia empresarial sugere várias estratégias diferentes que as unidades de negócios podem seguir, desde o crescimento agressivo da participação de mercado à consolidação, saída e liquidação. Segue a identificação de três fases citadas por Kaplan e Norton: crescimento, sustentação e colheita, demonstradas no Quadro 1.

\section{Perspectiva de clientes}

Para Costa (2006), o processo de contrução do BSC exige que os gestores reflitam sobre proposições genéricas, tais como "entregar mais valor ao cliente-alvo". Frequentemente, diferentes gestores tem diferentes entendimentos do que é esse valor e de quem é esse cliente. 0 detalhamento encadeado do mapa estratégico evita esse problema. Ele exige que os gestores discutam e definam quem é esse cliente-alvo e que valor é esse a ser entregue. Eles terão que definir quais atributos são importantes e qual o nível de excelência em cada um dos atributos importantes.

Assim, para definir o BSC da empresa, é necessário articular os objetivos e as metas para esses atributos, tais como tempo, qualidade, desempenho e serviço e preço, e traduzi-los em medidas específicas.
Segundo Kaplan e Norton (1997), na perspectiva dos clientes do Balanced Scorecard, as empresas identificam os segmentos de clientes e mercado nos quais desejam competir. Esses segmentos representam as fontes que irão produzir o componente da receita dos objetivos financeiros da empresa. Esta perspectiva permite que as empresas alinhem suas medidas essenciais de resultados relacionadas aos clientes - satisfação, fidelidade, retenção, captação e lucratividade - com segmentos específicos de clientes e mercado. Além disso, permitem a clara identificação e avaliação das propostas de valor dirigidas a esses segmentos. As propostas de valor são os vetores, os indicadores de tendências, para as medidas essenciais de resultados na perspectiva dos clientes.

As empresas precisam identificar os segmentos de mercado em suas populações atuais e potenciais de clientes, e depois selecionar os segmentos nos quais preferem atuar. A perspectiva dos clientes traduz a missão e a estratégia da empresa em objetivos específicos para segmentos focalizados de clientes e mercados que podem ser comunicados à toda organização, descrito no Quadro 2.

Depois de identificar e focalizar seus segmentos de mercado, a empresa deve cuidar dos objetivos e indicadores específicos. 0 grupo de medidas essenciais de resultados dos clientes é comum a todos os tipos

Quadro 1 - Medição dos temas financeiros estratégicos

\begin{tabular}{|c|c|c|c|c|}
\hline & & \multicolumn{3}{|c|}{ Temas estratégicos } \\
\hline & & Aumento e mix de receita & $\begin{array}{l}\text { Redução de custos/aumen- } \\
\text { to de produtividade }\end{array}$ & Utilização dos ativos \\
\hline \multirow{3}{*}{$\begin{array}{l}\text { Estratégia } \\
\text { da unidade } \\
\text { de negócios }\end{array}$} & Crescimento & $\begin{array}{l}\text { Aumento da taxa de vendas } \\
\text { por segmento. Percentual } \\
\text { de receita gerado por novos } \\
\text { produtos, serviços e clientes. }\end{array}$ & Receita/funcionário. & $\begin{array}{l}\text { Investimento (percentual de } \\
\text { vendas). P \& D (percentual } \\
\text { de vendas). }\end{array}$ \\
\hline & Sustentação & $\begin{array}{l}\text { Fatia de clientes e conta-alvo. } \\
\text { Vendas cruzadas. Percentual } \\
\text { de receita gerado por novas } \\
\text { aplicações. Lucratividade por } \\
\text { clientes e linhas de produtos. }\end{array}$ & $\begin{array}{l}\text { Custos versus custos dos } \\
\text { concorrentes. Taxas de re- } \\
\text { dução de custos. Despesas } \\
\text { indiretas (percentual de } \\
\text { vendas). }\end{array}$ & $\begin{array}{l}\text { Índices de capital de giro } \\
\text { (ciclo de caixa a caixa). ROCE } \\
\text { por categoria-chave de } \\
\text { ativo. Taxas de utilização dos } \\
\text { ativos. }\end{array}$ \\
\hline & Colheita & $\begin{array}{l}\text { Lucratividade por clientes e } \\
\text { linhas de produtos, percentual } \\
\text { de clientes não lucrativos. }\end{array}$ & $\begin{array}{l}\text { Custos unitários (por } \\
\text { unidade de produção, por } \\
\text { transação). }\end{array}$ & $\begin{array}{l}\text { Retorno. Rendimento } \\
\text { (throughput). }\end{array}$ \\
\hline
\end{tabular}

Fonte: KAPLAN; NORTON, 1997, p. 55. 
de empresa e inclui indicadores de: participação de mercado, retenção de clientes, captação de clientes, satisfação de clientes e lucratividade de clientes.

Quadro 2 - Segmento-alvo e lucratividade dos clientes

\begin{tabular}{lll}
\hline Clientes & Lucrativo & Não lucrativo \\
\hline Segmento-alvo & retenção & transformação \\
Segmento não específico & monitoração & eliminação \\
\hline
\end{tabular}

Fonte: KAPLAN; NORTON, 1997 p. 77.

A participação de mercado reflete a proporção de negócio em um determinado mercado (em termos de clientes, valores gastos ou volume unitário vendido). A captação mede, em termos absolutos ou relativos, a intensidade com que uma unidade de negócios atrai ou conquista novos clientes. Já a retenção de clientes controla a intensidade com que uma unidade de negócios retém ou mantém relacionamentos contínuos com seus clientes. A satisfação dos clientes mede o nível de satisfação de acordo com critérios específicos de desempenho dentro da proposta de valor. E a lucratividade dos clientes mede o lucro de cliente ou segmento, depois de deduzidas as despesas específicas necessárias para sustentar esses clientes (KAPLAN; NORTON, 1997).

\section{Perspectiva dos processos internos}

Para Costa (2006), as metas financeiras estabelecidas e as necessidades dos clientes norteiam os processos internos. As empresas necessitam definir os processos e as competências que precisam superar e definir as medidas adequadas para avaliar se o objetivo está sendo atingido. As técnicas e iniciativas devem ser escolhidas e priorizadas de acordo com a relevância para o cumprimento da estratégia. Assim, decisões sobre qualidade total, reengenharia, just-in-time, novas máquinas, novos equipamentos devem ser analisadas do ponto de vista do resultado final que produzirão, ou melhor, sob o critério de relevância para entregar aqueles atributos considerados estratégicos.

Segundo Kaplan e Norton (1997), para a perspectiva dos processos internos da empresa, os executivos identificam os processos mais críticos para a realização dos objetivos dos clientes e acionistas. As empresas costumam desenvolver objetivos e medidas para essa perspectiva depois de formular objetivos e medidas para as perspectivas financeiras e do cliente. Essa sequência permite que as empresas focalizem as métricas dos processos internos que conduzirão aos objetivos dos clientes e acionistas.

Os sistemas de medida de desempenho da maioria das empresas focalizam a melhoria dos processos operacionais existentes. As empresas costumam monitorar e melhorar os processos existentes, mesmo quando isso não é estratégico. 0 ganho de produtividade, frequentemente, é um objetivo em si mesmo. O BSC rompe essa lógica. Os investimentos e as mudanças de processos que aumentam a produtividade só são considerados se foram críticos para o sucesso da estratégia da organização.

\section{Relações de causa e efeito}

Segundo Padovese (2009), o Balanced Scorecard continua enfatizando a busca de objetivos financeiros, mas também inclui os vetores de desempenho desses objetivos. Procura medir o desempenho organizacional sob quatro perspectivas equilibradas: financeira, do cliente, dos processos internos da empresa, e do aprendizado e crescimento.

0 enfoque financeiro, que conclui os vetores operacionais e estratégicos, está relacionado com o objetivo da empresa e a visão do lucro como medida da eficácia empresarial, portanto, relaciona-se com o elemento mais importante de um sistema, que é o objetivo.

0 enfoque do cliente relaciona-se com o componente de saída do processo sistêmico, pois o cliente é que recebe os produtos e serviços gerados pelo sistema empresarial.

0 enfoque dos processos internos relaciona-se com o elemento processamento do sistema, ou seja, indicadores que monitorem os objetivos e metas para gestão dos processos de negócios.

0 enfoque do aprendizado e crescimento relaciona-se com os elementos das entradas ou recursos do sistema. No caso do Balanced Scorecard, a ênfase é com a capacidade do funcionário (o capital humano), o recurso mais importante do sistema empresa, caracterizado na Figura 1.

\section{Perspectiva do aprendizado e crescimento}

A quarta e última perspectiva é a do aprendizado e crescimento, esta oferece infraestrutura que 
possibilita a consecução de objetivos ambiciosos nas outras três perspectivas (KAPLAN; NORTON, 1997). Contemplando a mesma ideia, Rocha (2006) diz que os objetivos desta perspectivas são os vetores dos resultados excelentes nas três primeiras perspectivas do scorecard. Diante de funcionários motivados, a empresa terá bom desempenho nos processos internos, clientes satisfeitos e retorno financeiro desejado.

Muitas empresas não veem o treinamento e desenvolvimento de seus funcionários como investimento, e sim como um custo, o que dificulta a implantação de um sistema como o BSC.

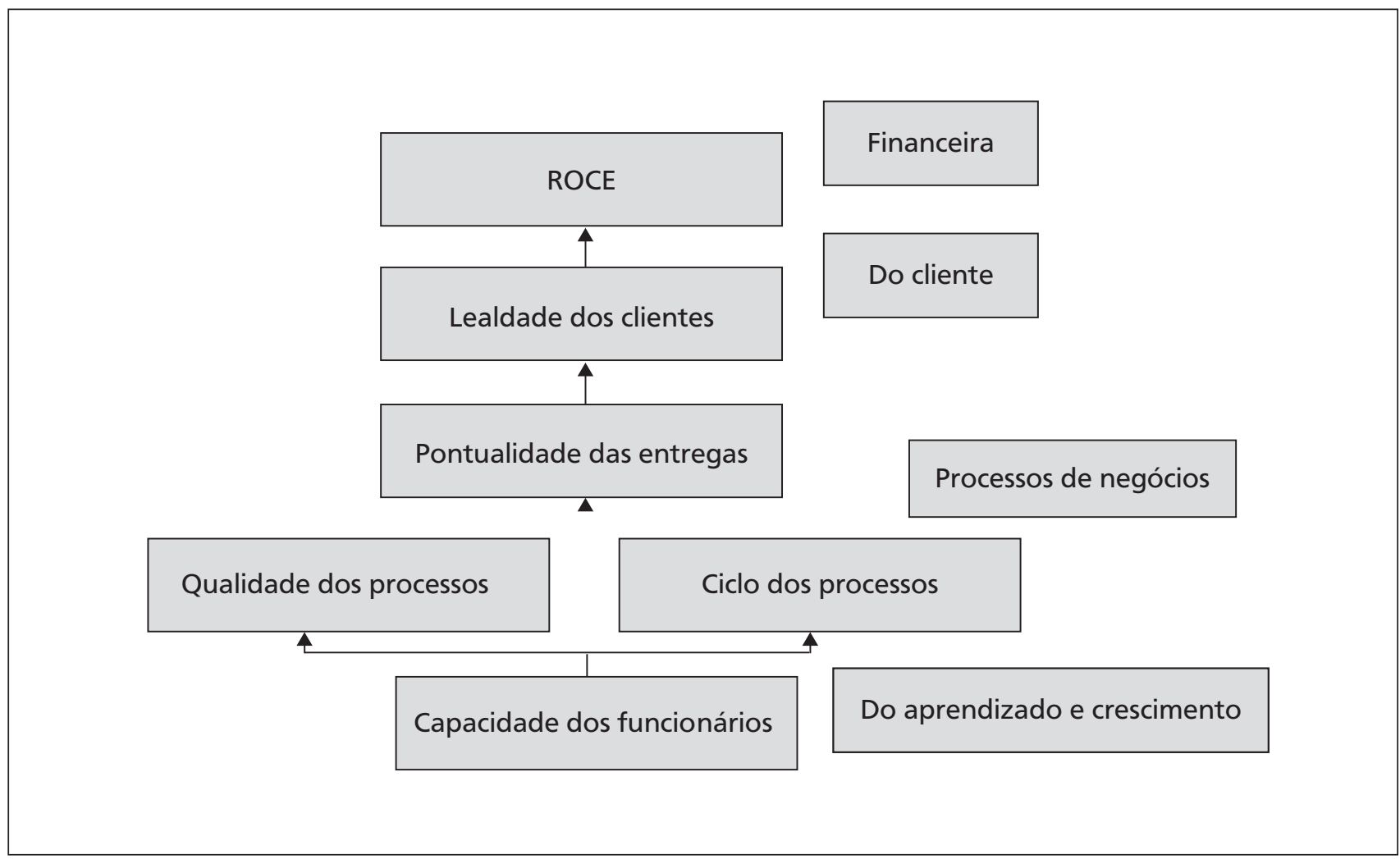

Figura 1 - Relações de causa e efeito da estratégia

Fonte: PADOVESE, 2009, p. 589.

De acordo com Kaplan e Norton (1997, p. 134), são medidas essenciais, conforme demonstrado na Figura 2:

a) a satisfação do funcionário - reconhece que colaboradores com o moral mais elevado tendem a ter clientes mais satisfeitos;

b) a retenção do funcionário - remete a objetivos que incentivem a permanência dos colaboradores na empresa, diante de uma saída significa perda de capital intelectual, o que não seria interessante para a empresa;

c) a produtividade dos funcionários - é a relação entre o moral do funcionário e o nível da sua habilidade, pela melhoria nos processos internos e clientes satisfeitos.

\section{Vetores}

A primeira sendo a mais importante, porque justifica as demais, uma vez que diante de um funcionário satisfeito, há retenção do funcionário e aumento na produtividade.

Um profissional comprometido, proativo, flexível e de bom relacionamento interpessoal influencia no crescimento da empresa, pois tende a oferecer serviços de melhor qualidade. Contudo, profissionais capacitados não nascem prontos, é necessário que cada indivíduo faça constantes autoavaliações para identificar suas qualidades e os pontos que precisam ser desenvolvidos (SILVA; SILVA, 2011). 


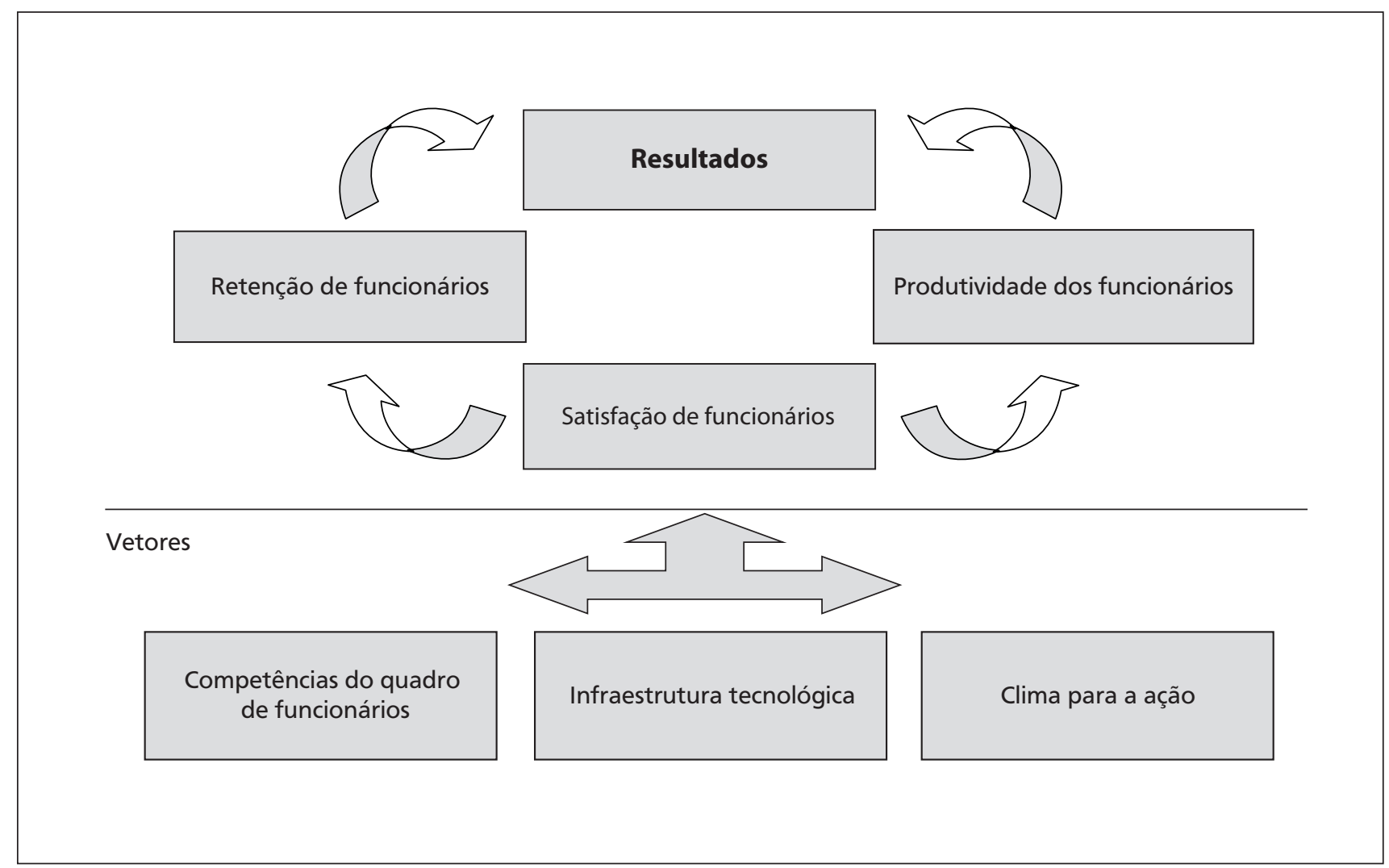

Figura 2 - A estrutura de medição do aprendizado e crescimento

Fonte: Adaptado de KAPLAN; NORTON, 1997, p. 135.

A partir da visualização dessas três medidas, Kaplan e Norton (1997) direcionam para três variáveis críticas: a reciclagem da força de trabalho, a capacidade dos sistemas de informação e a motivação, empowerment e alinhamento.

Para melhor entender a reciclagem da força de trabalho, identificam a necessidade dos funcionários passarem por atualizações, pois, à medida que a implantação do scorecard estabelece um nível de mudança e inovação, os mesmos precisam acompanhar a implantação, de forma a contribuir no processo. Sem este envolvimento o processo se torna inviável; a capacidade dos sistemas de informação dá o suporte necessário para que o funcionário desempenhe com eficiência suas atividades, com informações cruciais para um bom atendimento das necessidades do cliente; e a motivação, empowerment e alinhamento dão ao funcionário a importância que ele tem para a empresa, onde ele é ouvido e suas sugestões são compreendidas como ferramentas para o alcance dos objetivos organizacionais.

Sistema de avaliação de desempenho pode ser entendido como um processo sistemático de medição e comparação (MOMENI et al., 2011). 0 monitoramento dos resultados a partir de investimentos feitos em funcionários se torna de suma importância para um acompanhamento eficiente que gere retorno para a organização e funcione como um ciclo de benefícios entre empresa, funcionários e clientes.

\section{Os quatro processos do balanced scorecard}

Segundo Padovese (2009), o processo de elaboração e difusão do Balanced Scorecard é efetuado em quatro etapas: tradução da visão, comunicação e comprometimento, planejamento de negócio e feedback e aprendizado.

0 processo da tradução e visão traduz a missão da empresa de forma compreensível para os gestores divisionais. Isso ajuda os gestores a formar um consenso em torno da visão e estratégia da organização. As diretrizes estratégicas devem ser traduzidas de forma fácil em termos operacionais e oferecer orientação útil para as ações dos gestores. Kaplan e Norton (1997) alertam para as diferentes situações 
de mercados, segmentos de negócios, estratégias de produtos e ambientes competitivos que demandam diferentes sistemáticas de medição, requerendo, ainda, construção de indicadores capazes de sinalizar, consistentemente, que aspectos devem ser aprimorados e potencializados.

As declarações da missão empresarial devem ser expressadas como um conjunto integrado de objetivos e indicadores, que descrevem direcionadores de sucesso de longo prazo. Estes objetivos e indicadores devem ser aceitos por todos os gestores divisionais.

Já a comunicação e comprometimento permitem aos gerentes comunicar sua estratégia, para cima e para baixo na organização, e ligar os objetivos empresariais aos objetivos departamentais e individuais. O BSC proporciona aos gestores uma forma de assegurar que todos os níveis da organização entendam as estratégias de longo prazo e que tanto os objetivos departamentais quanto os individuais estão alinhados entre si.

0 processo do planejamento de negócios possibilita a empresa integrar seus planos comerciais e finaceiros. Nesta etapa, as estratégias e iniciativas da empresa são transformadas em indicadores para os planos dos gestores divisionais, bem como formar uma base para alocar recursos e estabelecer prioridades.

0 feedback e os processos de revisão de foco existentes concentram-se no fato de a empresa, seus departamentos ou seus empregados, isoladamente, terem alcançado suas metas financeiras orçadas. Com o balanced scorecard no centro de seus sistemas de gerenciamento, uma empresa pode monitorar os resultados de curto prazo a partir de três diferentes perspectivas adicionais - clientes, processos internos de negócios e aprendizado e crescimento - e assim avaliar a estratégia adotada à luz do recente desempenho. Uma das grandes contribuições que o BSC vem proporcionando às empresas é auxiliar face a dois pontos críticos, que seriam a mensuração eficiente do desempenho organizacional e a implementação da estratégia com êxito (DANTAS et al., 2010).

A apresentação do referencial teórico apresentado possibilita o melhor entendimento do que é a ferramenta do Balanced Scorecard e de como ela pode ser utilizada pela empresa para auxiliá-la na medição dos indicadores de desempenho, proporcionando um melhor controle e alavancando melhores resultados. Diante disto, pode-se responder como mensurar e controlar indicadores de desempenho para obtenção de melhores resultados financeiros e não financeiros, identificando indicadores de desempenho com a melhor aplicação para a empresa, analisando-os a partir das quatro perspectivas sugeridas pelo BSC.

$O$ conhecimento das quatro perspectivas do BSC reflete no desenvolvimento da pesquisa, pois a explicitação do tema em referência induz a um entendimento amplo e direcionado na construção do diagnóstico da empresa de pequeno porte, levando a um melhor entendimento da realidade vivenciada pelos gestores e funcionários da organização.

\section{Metodologia}

0 estudo realizado, quanto a sua natureza, caracterizou-se como uma pesquisa aplicada, descritiva e explicativa. Segundo Vergara (2006), a pesquisa descritiva expõe características e estabelece correlações entre variáveis de determinada população ou fenômeno e a pesquisa explicativa tem como principal objetivo esclarecer quais fatores contribuem de alguma forma para a ocorrência de determinado fenômeno. A estratégia de abordagem utilizada foi o estudo de caso em uma empresa de pequeno porte do Rio Grande do Norte. Segundo Dencker (2000), o estudo de caso trabalha com uma ou com poucas unidades de pesquisa, um indivíduo, um grupo, uma organização, um conjunto de organizações ou inclusive uma situação observada, aprofundando e detalhando os conhecimentos sobre esta, podendo ser realizada em campo ou não. 0 procedimento técnico utilizado para coleta de dados consistiu na aplicação de um questionário composto por dez questões abertas e uma fechada, a partir das quatro perspectivas do BSC. 0 universo para aplicação desta pesquisa foram os gestores e o tratamento de dados ocorreu de forma qualitativa. Leite (2008) define como pesquisa qualitativa aquela em que não são usados instrumentos estatísticos para comprovar o estudo.

\section{Resultados}

Diante dos dados coletados, foi possível perceber o contexto vivido atualmente na empresa. É uma empresa que cresceu no decorrer dos anos, incrementou o mix de produtos que trabalha, mas não mensura dados que poderiam trazer grande vantagem competitiva para a mesma.

A empresa não tem um planejamento estratégico bem definido, o que caracteriza um ponto crucial 
para a elaboração do BSC. Segundo Shaverdi, Akbari e Tafti (2011), na etapa inicial do BSC é importante coletar as ideias possíveis em relação ao desempenho através de entrevistas com gerentes de negócios e discutir sua visão, missão e estratégia. 0 planejamento estratégico de uma empresa é basicamente um mapa a ser trilhado pela empresa, pelo qual se identifica onde ela está, como ela quer estar e como ela vai fazer para alcançar seus objetivos, ou seja, direciona a empresa perante seu futuro. Um planejamento estratégico bem definido é o primeiro passo para a implantação do BSC, visto que dará o direcionamento para os demais procedimentos.

A comunicação da estratégia aos seus colaboradores será o próximo passo, pois dará aos mesmos a direção que a empresa realmente almeja. Nesta oportunidade será explicado o porquê do BSC, seus objetivos e deixaria claro as vantagens para todos.

Na perspectiva financeira foram identificadas várias falhas de gerenciamento, como não mensuração de custos e despesas que contribuem para a maximização de lucros. Por isso são sugeridas medidas e indicadores de desempenho para melhor mensurar esses custos, apresentado no Quadro 3:

Quadro 3 - Perspectiva financeira

\begin{tabular}{ll}
\hline Medidas & Indicadores \\
\hline Reduzir os custos & - Receita/custo por empregado \\
& - Margem bruta \\
Aumento da receita & - Crescimento da receita \\
& - Lucratividade por funcionário \\
\hline
\end{tabular}

Fonte: Dados da pesquisa.

Quando a gerência passar a ter esses dados mensurados, as decisões gerenciais serão mais acertadas, visto que as informações, ao cruzarem com o sistema de informação da empresa, serão mais concretas e claras.

Na perspectiva do cliente, a empresa tem uma equipe de telemarketing que faz um trabalho de acompanhamento de satisfação do cliente, mas não é preciso, pois essas informações não são analisadas de forma holística, o que traria para a empresa informações precisas. Na verdade, elas são analisadas separadamente, o que justifica possíveis falhas no relacionamento com o cliente e a mensuração devida dos dados.
O Quadro a seguir trata das medidas e indicadores nesta perspectiva (Quadro 4):

Quadro 4 - Perspectiva do cliente

\begin{tabular}{|c|c|}
\hline Medidas & Indicadores \\
\hline Fidelização do cliente & $\begin{array}{l}\text { - Retorno a empresa } \\
\text { - Índice de satisfação }\end{array}$ \\
\hline $\begin{array}{l}\text { Entrada de novos } \\
\text { clientes }\end{array}$ & $\begin{array}{l}\text { - Média de novos clientes por ano } \\
\text { - Percentual de respostas dos } \\
\text { clientes }\end{array}$ \\
\hline
\end{tabular}

Fonte: Dados da pesquisa.

Ao relacionamento com os clientes tem que ser dada a devida importância, visto que eles são o combutível para que a empresa continue trabalhando, e olhar para esta perspectiva com estima trará grandes benefícios para a empresa.

$\mathrm{Na}$ perspectiva dos processos não tem nenhum meio de mensuração na empresa, não é dada a real importância para esta modalidade gerencial, o processo é tratado mecanicamente (Quadro 5).

Quadro 5 - Perspectiva dos processos internos

\begin{tabular}{ll}
\hline Medidas & Indicadores \\
\hline $\begin{array}{l}\text { Aprimorar o tempo } \\
\text { do pedido }\end{array}$ & $\begin{array}{l}\text { - Tempo médio de entrega } \\
\text { Sistemas de }\end{array}$ \\
informação & - Nível de investimento em TI \\
\hline
\end{tabular}

Fonte: Dados da pesquisa.

Esta perspectiva dá à empresa visão de como suas atividades estão sendo executadas. Quando essas informações são mensuradas, possibilita-se à empresa verificar o andamento de suas atividades, se estão sendo realizadas conforme a estratégia definida.

$\mathrm{Na}$ perspectiva do aprendizado e crescimento prevê-se uma maior importância a ser dada ao seu colaborador. A mensuração é feita sob a seguinte ótica (Quadro 6).

O investimento em treinamento e desenvolvimento é crucial para o desempenho dos colaboradores em suas atividades, o incentivo à aprendizagem e o reconhecimento do trabalho desenvolvido são impulsionadores 
de uma atividade fielmente cumprida e alinhada à estratégia da empresa, se tornando vantagem competitiva no mercado. Segundo Fragoso (2009), no contexto atual, da mesma forma que exige-se pessoas capacitadas, as empresas também precisam estar dispostas a oferecer um ambiente favorável para o desenvolvimento de competências de sua equipe.

Quadro 6 - Perspectiva do aprendizado e crescimento

\begin{tabular}{ll}
\hline Medidas & Indicadores \\
\hline Motivação dos funcionários & $\begin{array}{l}\text { - Média de sugestões } \\
\text { - Índice de comprometimento }\end{array}$ \\
$\begin{array}{ll}\text { Treinamento e desenvolvi- } \\
\text { mento }\end{array}$ & $\begin{array}{l}\text { - Índice de investimento } \\
\text { anual }\end{array}$ \\
\hline
\end{tabular}

Fonte: Dados da pesquisa.

\section{Considerações finais}

Com a implementação do Balanced Scorecard a empresa terá condições de mensurar dados ainda não explorados, o que trará vantagem competitiva.

Diante do processo de estruturação do BSC, a empresa terá um desafio: visto que a cultura é muito forte, o que implica dizer qua há uma resistência a mudanças, faz-se necessário investir tempo com sensibilização para garantir o sucesso do método a ser implantado, mostrando todos os pontos positivos que vão poder extrair do mesmo e o quão será necessário o esforço e envolvimento de todos no processo como um todo.

A diretoria precisa começar a enxergar a empresa como um todo, mantendo os funcionários sempre a par da realidade, procurando ouvi-los. É preciso utilizar-se desta abertura de tal forma que ela contribua para o relacionamento interno e reflita na satisfação dos clientes e, consequentemente, em resultados financeiros, com intuito de traçar novas diretrizes estratégicas. Kaplan e Norton (1997) salientam que o objetivo de qualquer sistema de mensuração deve motivar todos os executivos e funcionários a implementar com sucesso a estratégia de sua unidade de negócios. A estratégia corporativa é vista como uma concepção de como agir, tendo em vista seus recursos e limitações, bem como as condições ambientais propícias ou ameaçadoras (CANHADA; RESE, 2009).

Ao desenvolver um Balanced Scorecard bem estruturado na estratégia e direcionado para atingir metas e objetivos, a empresa quebra vários paradigmas, o que impulsiona para inovações e lucros para todos que fazem parte do sistema: empresa, fornecedores, clientes e colaboradores. Este sistema deve ser sempre consultado com o fim de encontrar possíveis falhas que apontem a insatisfação das partes, podendo ser estrategicamente reformulado e readaptado à realidade.

A implementação do BSC é completa quando todos se propõem a participar ativamente do processo e quando a estratégia é respeitada servindo de orientação para o sistema. Kaplan e Norton (2004) afirmam que o processo de feedback e aprendizado da organização consiste na capacidade de aprendizado estratégico, ou seja, fazer da gestão estratégica um processo contínuo.

Vê-se que a importância de todas as perspectivas (financeira, clientes, processos internos e aprendizagem e crescimento) é indiscutível, pois elas agem como um ciclo, de forma que uma impulsiona a outra. 0 funcionamento de ambas é indispensável para o aproveitamento positivo do sistema gerencial aplicado.

Por fim, foi possível, a partir do estudo de caso, conhecer a percepção dos gestores responsáveis pela empresa sobre a compreensão e adoção dos conceitos relacionados ao BSC, caracterizando seu desempenho e, consequentemente, traçar diretrizes que proporcionem vantagens competitivas mais eficazes, alicerçadas por dados reais do mercado, além de reduzir custos inerentes às atividades meio e fim, propiciando, dentre outras vantagens, consolidar processos inovadores e empreendedores.

\section{Referências}

AZARBAD, M. et al. A framework to select commercial bank partner using fuzzy BSC-DEA method. Management Science Letters, v. 1, n. 4, p. 467-480, 2011.

CANHADA, D. I. D.; RESE, N. Contribuições da "estratégia como prática" ao pensamento em estratégia. Revista Brasileira de Estratégia, v. 2, n. 3, p. 273-289, 2009.

COSTA, A. P. P. Balanced scorecard: conceitos e guia de implementação. São Paulo: Atlas, 2006.

DANTAS, J. E. et al. Análise do modelo de construção, implementação e acompanhamento do balanced scorecard em uma organização do setor educacional. In: CONGRESSO NACIONAL DE EXCELÊNCIA EM GESTÃO, 6., 2010, Niterói. Anais... Niterói: CNEG, 2010. 
DENCKER, A. de F. M. Métodos e técnicas de pesquisa em turismo. 4. ed. São Paulo: Futura, 2000.

FRAGOSO, S. de A. Gestão estratégica de pessoas como fonte de vantagens competitivas nas organizações. Revista Brasileira de Estratégia, v. 2, n. 3, p. 307-315, 2009.

KAPLAN, R. S.; NORTON, D. P. A estratégia em ação: balanced sorecard. Rio de Janeiro: Campus, 1997.

KAPLAN, R. S.; NORTON, D. P. Organização orientada para a estratégia. Rio de Janeiro: Campus, 2000.

KAPLAN, R. S. Mapas estratégicos balanced scorecard: convertendo ativos intangíveis em resultados tangíveis. Rio de Janeiro: Elsevier, 2004.

LEITE, F. T. Metodologia científica: métodos e técnicas de pesquisa: monografias, dissertações, teses e livros. Aparecida: Idéias \& Letras, 2008.

LUZ, D. F. Transpondo custos para times de chão de fábrica: um estudo de caso na General Motors. Revista Brasileira de Estratégia, v. 2, n. 3, p. 247-256, 2009.

MELLO, L. B. et al. Organizacionais: proposição de um modelo baseado no balanced scorecard. In: CONGRESSO NACIONAL DE EXCELÊNCIA EM GESTÃO, 6., 2010, Niterói. Anais... Niterói: CNEG, 2010.

MOMENI, M. et al. A Fuzzy MCDM Approach for evaluating listed private banks in tehran stock exchange based on balanced scorecard. International Journal of Business Administration, v. 2, n. 1, p. 80-97, 2011.
PADOVESE, C. L. Contabilidade gerencial: um enfoque em sistema de informação contábil. 5. ed. São Paulo: Atlas, 2009.

ROCHA, J. S. da; SELIG, P. M. Utilizando o balanced scorecard para gerenciar pequenas e médias empresas. Disponível em: <www.contabeis.ufba.br>. Acesso em: 22 abr. 2006.

SHAVERDI, M.; AKBARI, M.; TAFTI, S. F. Combining fuzzy MCDM with BSC approach in performance evaluation of iranian private banking. Journal Advances in Fuzzy Systems. v. 2011, p. 1-12, 2011.

SILVA, D.; SILVA, A. A aplicação do modelo de gestão por competências como ferramenta de melhoria no desempenho humano nas organizações. Revista Textura, v. 1, n. 1, 2011.

VERGARA, S. C. Projetos e relatórios de pesquisa em administração. 7. ed. São Paulo: Atlas, 2006.

Recebido: 23/09/2011

Received: 09/23/2011

Aprovado: $18 / 10 / 2011$

Approved: 10/18/2011 